Introduction Workplace social capital (WSC) is hypothesised to be beneficial for employee health. We sought to examine the association between changes in WSC in relation to changes in HbA1c levels.

Methods Analyses included 2778 men and 684 women aged 65 and under working at six companies in Japan from the JHOPE Study. The first survey was conducted between October 2010 and December 2011, and two follow-up surveys were conducted at approximately annual intervals. Questionnaires inquiring about workplace social capital and other characteristics were administered at each survey. Blood samples were obtained from participants at baseline and at the following two surveys. Linear regression analysis was performed to assess the cross-sectional and longitudinal association between WSC and HbA1c levels using Generalised Estimating Equations.

Result For women, higher level of WSC was cross-sectionally associated with lower HbA1c (standardised regression coefficient $(\beta)-0.020,95 \% \mathrm{CI}$ : -0.033 to -0.007$)$. Longitudinally, similar associations were observed $(\beta-0.016$, 95\% CI: -0.030 to -0.003$)$. No association was found among men. All explanatory variables were standardised before inclusion in each analysis.

Discussion WSC may have beneficial effects on glycometabolism in working women. The gender difference in associations may be partially explained by the socio-cultural context. Our findings lend weight to the notion that the pattern of association between WSC and HbA1c is both culturally contingent and gender-specifi.

\section{AN EVALUATION OF WORKPLACE STRESS IN AN QATARI OIL AND GAS COMPANY}

A El Makaty*. Qatar Engineering and Construction Company, Doha, Qatar

\subsection{6/oemed-2018-ICOHabstracts. 1733}

Introduction This research aims to identify and to evaluate workplace stress risks in an oil and gas contracting company in the State of Qatar. The study is conducted using a specific work-related stress risk assessment methodology developed by the Italian National Institute for Insurance against Accidents at Work (INAIL). The goal of this research is to propose efficient control measures to tackle such risks and to enhance employee job satisfaction in the company. Moreover, the study focuses on investigating the aspects of work demands, controls and other associated factors with work stress that might be adversely affecting the employees in the core operations of the organisation.

Methods Both qualitative and quantitative methods of research were applied throughout the study using the INAIL approach. The methodology is applied to an intended convenience sample of 210 employees of the Maintenance and Shutdown Department in the company, which observes a work force of 1662 employees, contributing to a sample value of $12.5 \%$.

Results Overall results demonstrate low presence of work stress. However, there is a clear need for improvement in the areas of demands, control, relationships and change with particular minor considerations for managerial support area.

Conclusion The findings from this research established a firm ground intended for applying a work-related stress improvement strategy in the company which includes:
- the application of the INAIL method tailored for the organisation's use. However, this can be done when both checklist and questionnaire are applied, regardless of the lowrisk scores, in order to assess critical sub-areas;

- HSE indicator tool questionnaire should be elaborated more for the employees, particularly for the blue collar workers;

- establishing a commitment towards the management of work stress through a clear policy, trainings and education on psychosocial factors is essential for the success of this tool.

\section{IS WORKPLACE BULLYING AN INDEPENDENT RISK FACTOR FOR MUSCULOSKELETAL DISORDERS? A STUDY WITH BRAZILIAN CIVIL SERVANTS}

${ }^{1}$ Fernando Feijo, ${ }^{2}$ Eduarda Buriol, ${ }^{3}$ Cristiane Bunchen, ${ }^{2}$ Paulo Antonio Oliveira, ${ }^{3}$ Mayte Amazarray. ${ }^{1}$ Federal University Of Pelotas, Pelotas, Brazil; ${ }^{2}$ Federal University of Rio Grande do Sul, Porto Alegre, Brazil; ${ }^{3}$ Federal University of Health Sciences, Porto Alegre, Brazil

\subsection{6/oemed-2018-ICOHabstracts. 1734}

Introduction Workplace bullying has been described as an important determinant for many health outcomes, such as depression, suicidal ideation and sleeping problems. However its role as a possible determinant of musculoskeletal disorders is still on discussion. We aimed to evaluate the independent association between workplace bullying and neck/upper limb musculoskeletal pain in a sample of Brazilian civil servants.

Methods Cross-sectional study with a sample of 1616 workers from the Brazilian Federal Judiciary. The Negative Acts Questionnaire (NAQ-r) was used to measure bullying at work and an adapted version of the Nordic Musculoskeletal Questionnaire (NMQ) was used to evaluate neck and upper limb musculoskeletal pain. Poisson and logistic regressions were used to test and estimate associations of interest, controlling for confounders.

Results The overall prevalence of frequent (weekly or daily) neck and upper limb musculoskeletal pain was 49.9\%. The prevalence of workplace bullying was $17.0 \%$. In the regression analysis controlling for social, demographic and occupational confounders, workers exposed to bullying (weekly or daily negative acts) presented a 2.04-fold higher prevalence of neck and upper limb musculoskeletal pain than those who did not suffer bullying $(\mathrm{p}<0.001)$.

Discussion Our findings suggest that workplace bullying can be an independent risk factor for musculoskeletal pain in workers. New longitudinal studies are needed in order elucidate the role of workplace bullying in determining occupational musculoskeletal disorders.

\section{STUDY OF STRESS IN THE WORKPLACE: CASE OF A PORT AUTHORITY IN ABIDJAN}

Aka Irel Arnaud, Guiegui Chimene, Tchicaya Francois, Nguessan Linda, Kra Anny, Wognin Barthelemy. Universite Felix Houphouet Boigny, Abidjan, Côte d'ivoire

10.1136/oemed-2018-ICOHabstracts.1735

Introduction Work stress is defined as the adverse physical and psychological reaction that occurs when the demands of the job do not match the worker's needs, abilities or resources. It negatively impacts the health of workers and the 